sella Turcica demonstrable by X-rays was the exception and not the rule in these cases was no argument against the truth of the theory. Dr. de Schweinitz was inclined to suggest as a supplement to Fisher's view his own conception of the transference of toxins from the hypophysis to the chiasma.

In Part $\tau$, the appearance of the discs was pointed out, the best methods of the radiologist were indicated; the significance of the various deformations of the sella Turcica was discussed-surgical treatment was a subject outside the sphere of the lecture--but the methods and value of organotherapy were reviewed, as well as the effects of X-rays and radium, particularly when used subsequent to operation.

A complete bibliography of the whole subject is appended to the lecture, and cannot fail to be of the greatest assistance.

It is impossible to do justice to so valuable and so interesting a lecture in the space at our disposal, and especially in the absence of the drawings, fields and diagrams with which it is illustrated. Above all the absence of the magnetic personality of the lecturer is a defect for which there can be no compensation.

\title{
The Aetiology of Miners' Nystagmus
}

Every reader will recall the first Report of the Miners' Nystagmus Committee which was published last year. After a fuil and impartial discussion the Committee concluded that defective illumination was the essential factor in the causation of the disease. Other factors, such as position, alcoholism, hereditary predisposition, errors of refraction were considered to be merely of secondary importance. These views, reached after a careful review of the subject, have been generally adopted. Dr. A. S. Percival, however, (British Medical Journal, May 5 and June 9, 1923), considers, as did the late Simeon Snell, that the primary factor is to be found in the constrained position of the eyes assumed by coal-hewers. He bases his views upon figures obtained from thirty-two pits in the counties of Northumberland and Durham. Of 36,232 men employed by these mines 11,383 were hewers and 24,849 were nonhewers. One hundred and three of the former and fifty-nine of the others acquired nystagmus, in other words, the percentage of hewers with nystagmus was 0.949 , and of the others 0.2374 . A new theory has also been developed by Dr. Frederick Robson in two papers recently read by him before the South Wales Institute of Engineers. Briefly, Robson believes that the chief cause of miners' nystagmus is the emanations of noxious gases from coal which has been recently cut. He particularly specifies carbon monoxide in this connection. He points out that, in the South Wales and Monmouthshire coal field there is a progressive diminution in the 
volatile matter in passing from east to west, and a corresponding decrease in the nystagmus. In the meantime we feel that it would be a mistake to disregard the recommendation of the Miners' Nystagmus Committee, namely, to improve the illuminating conditions under which the miners work.

\section{ABSTRACTS}

\section{I.-CARCINOMA OF THE CHOROID}

Greenwood, Allen (Boston, Mass.).-Carcinoma of the choroid. Internat. Congress of Ophthal., April, 1922.

The salient facts of the four cases of carcinoma of the choroid reported by Greenwood were as under: 1. A man came on account of acute glaucoma of one eye. The fundus of that eye, after the glaucoma had been relieved by miotics, showed in one part a separation of the retina, covering a flat, greyish-white mass. The liver was enlarged, and as it seemed doubtful if the case was one of sarcoma or carcinoma, the eye was not removed. Prior to death, the brain became involved. At the autopsy the primary source of the general carcinomatosis was found to be the prostate. The organs more particularly involved were the lungs, pleura, peribronchial glands, liver, brain, and eye. In this case the eye condition was the first to call attention to the possibility of disease in other parts of the body. 2. A woman of 48 complained of one eye, the sight of which was reduced to hand movements in the outer field. Retinal separation was found, through which could be seen a white mass raised towards its central part about 3D. and flattening out in all directions. It is compared by the author to some substance such as cheese inserted under the retina. Patient found to be affected with cancer of the breast, involving lung and axillary glands. Some four months later carcinoma found in the other eye. Death from cerebral involvement. 3. Woman, aged 60 years, vision failing in both eyes for several months. Two years previously breast amputated and axilla cleared of carcinomatous glands. Detachment of retina, with underlying greyish mass, in each eye. Patient died with cerebral symptoms. 4. Woman, aged 36 years, R.V. 20/30 a very flat, round, white, discoid subretinal mass found down and out from macula of R.E. History of operation about a year previously for mammary cancer. $\mathrm{X}$-ray examination showed extensive involvement of one lung. 